\title{
REGIONALIZAÇÃO, PRESERVAÇÃO E INOVAÇÃO EM ATIVIDADES CULTURAIS: UMA ANÁLISE EXPLORATÓRIA A PARTIR DO REFERENCIAL DE ARRANJOS PRODUTIVOS LOCAIS
}

\author{
REGIONALIZATION, PRESERVATION AND INNOVATION IN CULTURAL ACTIVITIES: AN \\ EXPLORATORY ANALYSIS FROM THE REFERENCE LOCAL PRODUCTIVE ARRANGEMENTS
}

Marcelo Gerson Pessoa de Matos

Professor adjunto do Instituto de Economia da Universidade Federal do Rio de Janeiro Rio de Janeiro (RJ), Brasil.

\section{Fabiano Geremia}

Professor adjunto da Universidade Federal de Santa Maria - Santa Maria (RS), Brasil.
Data de recebimento: $30-07-2013$ Data de aceite: 18-07-2014

\section{RESUMO}

O objetivo deste trabalho é avaliar, a partir do referencial de Arranjos Produtivos Locais (APL), as perspectivas de desenvolvimento virtuoso e sustentável de atividades culturais no Brasil. O estudo se baseia em uma análise comparativa dos resultados de oito estudos empíricos em APLs centrados em atividades culturais e 28 estudos empíricos em APLs em segmentos manufatureiros e agroindustriais. Todos os estudos foram realizados a partir do mesmo referencial metodológico, baseado no levantamento de dados primários junto aos produtores, com o emprego de questionários semi-estruturados. Observa-se que os esforços direcionados à inovação, com destaque para a categoria das inovações artísticas e estéticas, e aqueles direcionados à preservação se complementam num processo dinâmico de evolução. Diversos subsistemas e as capacitações técnicas/produtivas, organizacionais e artísticas se articulam para a produção de manifestações e produtos com características únicas. O estoque de conhecimentos, majoritariamente tácito, se encontra fortemente enraizado no território local e sua preservação e difusão é fortemente determinada pelos processos interativos. As relações sistêmicas desenvolvidas nos APLs culturais conduzem a significativos incrementos das capacitações, constituindo fatores decisivos para a competitividade/atratividade dos agentes individuais e dos APLs como um todo.

Palavras-chave: atividades culturais; regionalização; arranjos produtivos locais; competitividade, atratividade e sustentabilidade.

\section{ABSTRACT}

The objective of this study is to analyze, based on the conceptual framework of local productive arrangements (LPA), the perspectives for a virtuous and sustainable development of cultural activities in Brazil. The study is based on the comparative analysis of eight empirical studies on LPAs focusing on cultural activities and 28 empirical studies on LPAs focusing on manufacturing and agroindustrial segments. All studies used the same methodological framework, based on primary data collection through interviews with producers, using semi-structured questionnaires. It can be observed that efforts aimed at innovation, focusing on those related to aesthetic and artistic innovations, and those directed at preservation complement each other in the dynamic process of evolution. Several sub-systems and the technical/productive, organizational and artistic capabilities converge for the production of manifestations and products with unique characteristics. The knowledge base, heavily tacit, is deeply rooted in the local environment, and its preservation and diffusion are directly influenced by the interactive processes. The systemic relations developed in the cultural LPAs lead to significant enhancements in the capabilities, turning out to be decisive for the competitiveness and attractiveness of the individual agents and of LPAs as a whole.

Keywords: cultural activities; regionalization; local productive arrangements; competitiveness, attractiveness and sustainability. 


\section{INTRODUÇÃO}

O presente trabalho busca contribuir com o avanço da análise da cultura em uma perspectiva administrativa e econômica no sentido de melhorar o entendimento das formas de desenvolver meios de atribuir valor econômico real à riqueza cultural. Neste aspecto, a teoria e prática administrativa podem contribuir no gerenciamento e condução do desenvolvimento de atividades culturais virtuosas para o desenvolvimento econômico e social. Embora a relevância da cultura para o processo de desenvolvimento não seja circunscrita a um momento histórico específico, observa-se interesse e destaque crescentes do conjunto de atividades produtivas relacionadas à cultura no período recente. Especialmente, a produção de intangíveis ganha destaque com a introdução do paradigma tecnológico baseado em tecnologias da informação e comunicação - TICs.

Os argumentos em prol da relevância das atividades culturais vão além daqueles relacionados a grandezas econômicas. A importância da diversidade cultural é ressaltada no atual período, no qual se aprofunda a tentativa de homogeneizar padrões de consumo para dar vazão à acelerada produção e venda de bens e serviço de massa, estandardizados. Assim, o conceito de diversidade se coloca como chave nesta discussão. Quanto mais denso e rico o conteúdo cultural dos grupos sociais, maiores as possibilidades de enfrentamento dos desafios associados ao desenvolvimento empresarial e econômico, bem como a inserção na economia nacional e global (FURTADO, 1983; 1984).

A cultura, de forma ampla e enquanto atividade produtiva, é de suma importância para o processo de desenvolvimento. Tendo em vista tal perspectiva, destaca-se que os esforços de construção de um referencial econômico de análise adequado ainda são incompletos. No Brasil, muitos dos esforços têm se centrado na caracterização e dimensionamento das atividades (em termos de pessoal ocupado, renda gerada e valor agregado). Esforços hercúleos de exploração de estatísticas existentes (pouco adequadas) são relevantes para se conhecer melhor o objeto com qual se está lidando em termos agregados, mas não constitui um fim em si. Além de entender sua estrutura e dimensão, é de fundamental importância entender sua dinâmica.
Para avançar neste campo, o presente estudo propõe a aplicação do referencial evolucionário e de Arranjos e Sistemas Produtivos e Inovativos Locais à cultura. Especialmente relevante é o potencial que este referencial oferece de delinear perspectivas concretas de desenvolvimento das atividades produtivas relacionadas à cultura. Busca-se identificar os elementos e processos que condicionam a competitividade/atratividade das atividades culturais e seu potencial de desenvolvimento.

Além dessa introdução, esse trabalho encontra-se dividido em seis seções. A segunda seção apresenta o referencial conceitual e o levantamento de hipóteses. A terceira seção apresenta os procedimentos metodológicos. Na quarta seção, são discutidos os processos inovativos e interativos nos APLs. Na quinta seção, analisa-se a articulação dos agentes com o ambiente local. Na sexta seção, a discussão se centra nos determinantes de desenvolvimento dinâmico e sustentável das atividades culturais. Na conclusão, são propostos alguns desdobramentos desta análise.

\section{ARRANJOS PRODUTIVOS LOCAIS EM ATIVIDADES CULTURAIS}

A partir da confluência de perspectivas das escolas estruturalista e evolucionária, elabora-se o conceito e a abordagem metodológica de Arranjos e Sistemas Produtivos e Inovativos Locais (ASPILS), pela qual se orienta o presente trabalho. A partir da proximidade territorial nos APLs, manifestam-se importantes economias de aglomeração, como o acesso a conhecimentos e capacitações, mão-de-obra especializada, matérias-primas e equipamentos, etc. A interação direta entre agentes que compartilham códigos comuns de comunicação e de convenções e normas reforça a confiança mútua, caracterizando um ambiente propício para a geração, compartilhamento e socialização de conhecimentos por parte de empresas, organizações e indivíduos (CAMPOS et al., 2003; BRITTO, 2003).

A abordagem evolucionária destaca que a capacidade de inovar constitui aspecto fundamental da competitividade de organizações, regiões e países. Define-se competitividade como a capacidade de uma organização formular e implementação de estratégias concorrenciais, que Ihe permitam ampliar ou conservar uma posição sustentável no mercado. A competitividade sustentada e dinâmica depende principalmente da capacidade de 
aprendizagem e de criação de competências desenvolvidas pelos agentes para produzir e inovar. Esta concepção de vantagem competitiva sustentável e dinâmica se coloca em oposição à noção de "competitividade espúria" (FANJZYLBER, 1988) ou "estática".

O fenômeno tem levado um número crescente de estudiosos a se debruçarem sobre a "economia da cultura" e a mensuração da capacidade que a sociedade tem demonstrado de obter "valor econômico" a partir de atividades denominadas "culturais". Na condição de mercadoria, a cultura está inserida na lógica da produção capitalista, caracterizada pela expansão dos mercados através da concorrência entre "novas" e "velhas" mercadorias. A criação e reprodução de manifestações culturais geram a retração, transformação e, no limite, eliminação de outras manifestações previamente existentes. Conforme destaca Barbieri da Rosa et al. (2013), identifica-se, portanto, uma dinâmica que é essencialmente a da concorrência schumpeteriana, na qual inovações destroem velhos mercados e criam novos, gerando lucro aos inovadores e transformando as estruturas.

Alguns estudos destacam as principais características das atividades culturais (ou criativas) (O'CONNOR, 1999):

1. estreita articulação entre a esfera global e a local e entre grandes e pequenas empresas;

2. predominância de empreendimentos de micro e pequeno porte e grande número de autônomos, que se organizam em centros urbanos e aglomerações produtivas;

3. significativas economias de aglomeração, resultantes do uso de infra-estrutura física e de comunicações, da difusão de conhecimentos tácitos através de redes de interação, formais e informais - que fomentam a criatividade e a inovação - e da cooperação na execução de etapas produtivas e criativas.

Esta configuração das atividades produtivas é determinada e reforçada por características específicas dos seus produtos, processos produtivos e de consumo (CAVES, 2003):

1. a natureza coletiva da produção criativa e a necessidade de desenvolver e manter times criativos com capacitações complementares;
2. habilidades verticalmente diferenciadas e;

3. a necessidade de coordenar diversas atividades criativas dentro de um espaço de tempo geralmente curto.

Portanto, uma primeira hipótese deste trabalho é que ocorram ganhos de eficiência produtiva, relacionados à racionalização do uso dos fatores de produção e à maior eficiência na articulação das diferentes etapas produtivas. Destaca-se o compartilhamento dos mesmos fornecedores de insumos e prestadores de serviços, o uso da mesma infra-estrutura física (instalações e equipamentos) e a articulação em redes tecno-produtivas locais. Tais articulações contribuiriam para significativos incrementos de competitividade/atratividade.

Outro fator que ganha centralidade neste referencial analítico de ASPILs é o conhecimento. A aprendizagem se caracteriza como o processo interativo, de caráter cumulativo, que permite incorporar novos conhecimentos aplicados ao desenvolvimento, produção e comercialização de bens e serviços (LUNDVALL, 1992; CIMOLl; GIUSTA, 2000; COHENDET; STEINMUELLER, 2000). Nas atividades culturais, a forma de conhecimento mais importante é aquela associada à qualidade de atividades culturais. Este é um conhecimento essencialmente tácito, que se manifesta na forma de habilidades dos agentes. Os conhecimentos associados a práticas, rotinas e habilidades são impossíveis de serem codificados e difíceis de serem transferidos, mas têm um papel primordial para o sucesso inovativo nas mais variadas atividades produtivas (CASSIOLATO; LASTRES, 1999). O que é específico às atividades culturais é o fato de que o mesmo conjunto de conhecimentos tácitos e habilidades construam o principal insumo, o processo produtivo e o próprio produto resultante.

Portanto, considera-se como segunda hipótese deste trabalho que os conhecimentos tácitos sejam especialmente relevantes e determinantes nas atividades culturais e que os processos de difusão são potencializados pela interação direta dos agentes em APLs.

A consolidação de práticas de cooperação constitui importante forma de intensificar e ampliar os potenciais impactos da interação entre os agentes em APLs (BRITTO, 2004). Dentre os diferentes tipos de práticas cooperativas, destaca-se a cooperação produtiva, que tem como objetivo a obtenção de economias de escala e de escopo, bem 
como incrementos de qualidade e produtividade, e a cooperação inovativa, que tem como objetivo a diminuição de riscos, custos, tempo e, principalmente, o aprendizado interativo. Outra hipótese é que a cooperação se mostra especialmente significativa em atividades de base cultural, devido ao fato de a estreita interação produtivo-criativa estar intimamente ligada ao caráter coletivo da produção e consumo artístico e cultural e à grande complementaridade entre os diversos atores e suas capacitações.

No cerne dos argumentos que sublinham a especial articulação das atividades culturais com seu território está o conceito de identidade. Santos (2000) enfatiza que a proximidade em termos dos valores e percepções de pertencimento como elemento central caracteriza grupos sociais específicos em seu espaço de convivência local. No caso das atividades culturais, o próprio ato de compartilhamento e (re)construção destes aspectos simbólicos, em grande parte, encerra em si a própria atividade produtiva que ele facilita.

Portanto, o conhecimento cultural não é apenas tácito, mas também fortemente enraizado e relacionado a um grupo social específico. Tais conhecimentos constituem, portanto, um rico ativo específico da sociedade, podendo se constituir em importante diferencial competitivo de atratividade. Trata-se de um capital cultural em domínio do grupo social. A própria escolha do termo capital aponta para a possibilidade de este se depreciar, se transmutar em outras formas de capital e, assim, inclusive, ser apropriado por terceiros.

A interação entre os diferentes agentes em APLs é balizada por diferentes arcabouços institucionais e estruturas de governança. Esta última refere-se aos modos de coordenação entre os diferentes atores e suas atividades, que envolvem da produção à distribuição de bens e serviços, bem como o processo de geração, uso e disseminação de conhecimentos e de inovações (CASSIOLATO; SZAPIRO, 2003). Uma instância de coordenação especialmente importante nas atividades culturais é o poder púbico. Muitas atividades se valem e dependem da utilização do espaço público, muitas dependem de infra-estruturas de escala mínimaincompatível com as possibilidades de agentes e organizações culturais individuais. Assim, o poder público assume importante papel de interlocutor e, no caso extremo, co-produtor de muitas manifestações culturais. Portanto, argumenta-se que as formas de coordenação, intervenção e participação nos processos de decisão locais se revelam de suma importância para que o produto gerado apresente atrativo e seja oferecido de forma eficiente.

O argumento central deste trabalho é de que os processos de geração e difusão de conhecimentos, tácitos e codificados, que se materializam nas capacitações produtivas e inovativas, os processos de inovação e preservação, interagindo em um processo dinâmico de criação do novo e as articulações dos agentes produtivos entre si e com o território como um todo são vetores centrais para a construção desta competitividade/atratividade dinâmica e sustentada. O referencial de APLs contribui para lançar luz sobre estes fatores.

\section{PROCEDIMENTOS METODOLÓGICOS}

Este estudo aborda os resultados de estudos empíricos em oito APLs centrados em atividades culturais: o APL do carnaval do Rio de Janeiro, o caso da festa de São João de Campina Grande, o Forró em Fortaleza, o carnaval de Salvador e os APLs de cinema e audiovisual do Rio de Janeiro, Porto Alegre, Recife e Goiânia'. Estes são comparados a um conjunto amplo de estudos realizados em APLs de outros segmentos diversos, que não são centrados em atividades culturais² ${ }^{2}$ Possibilita-se, assim, uma comparação das atividades culturais com outras atividades, pesquisadas no escopo de um programa de pesquisa comum e com o emprego do mesmo referencial conceitual e analítico.

Os estudos foram realizados entre os anos de $2006 \mathrm{e}$ 2010 e empregaram o mesmo referencial analítico de APLs ${ }^{3}$.

\footnotetext{
Disponíveis em www.redesist.ie.ufrj.br

2 Os casos referidos englobam os ASPILs: Biotecnologia em Belo Horizonte/MG; Calçados em Birigui/SP; Confecções de Bonés em Apucarana/PR; Confecções em Cabo Frio/RJ; Confecções em Campina Grande/PB; Confecções em Colatina/ES; Confecções em Jaraguá/GO; Confecções em Natal/RN; Confecções em Petrópolis/ $\mathrm{RJ}$; Confecções em Tobias Barreto/SE; Confecções/Bordados Infantis em Terra Roxa/PR; Confeções/Bordado em Ibitinga/SP; EletrometalMecânico na Microrregião de Joinville/SC; Eletrônica e Telecomun. em Santa Rita do Sapucaí/MG; Equipamentos Odontológicos em Ribeirão Preto/SP; Fornecedores da Ford em Camaçari/BA; Informática em Ilhéus/BA; Informática em Recife - PE; Madeira na Região do Vale do Iguaçú - SC/PR; Materiais Plásticos na Região Sul de Santa Catarina/SC; Móveis em Linhares/ES; Móveis em Ubá/MG; Móveis na Grande Vitória/ES; Móveis na Região Oeste de Santa Catarina/SC; Pesca em Foz do Itajaí/SC; Petróleo e Gás em Macaé/RJ; Software em Brasília/DF; Software em Curitiba/PR.

3 Para uma discussão detalhada sobre a aplicação deste referencial para atividades culturais, ver Matos (2011).
} 
Dentre outros elementos, destaca-se o emprego de um questionário padrão a ser aplicado aos agentes culturais nos APLs investigados. Este questionário apresenta uma série de questões agrupadas em cinco blocos:

1. caracterização dos empreendimentos;

2. desempenho produtivo;

3. processos inovativos, de aprendizagem e de cooperação;

4. articulações com o ambiente local;

5. políticas públicas.

A análise, neste artigo, é de caráter exploratório e se baseia nos resultados obtidos para questões relacionadas aos blocos três e quatro. As informações obtidas foram agregadas em índices de importância. O índice de importância para o conjunto dos APLs culturais foi elaborado a partir da média aritmética das respostas de cada agente entrevistado. A resposta de um agente com relação a um processo investigado podia assumir os seguintes valores: 0 se irrelevante; 0,33 se de baixa; 0,66 se de média; e 1 no caso de alta importância ou intensidade. Assim, tais índices de importância apresentam valores que variam entre 0 e 1, sendo este último representativo dos processos mais intensos ou importantes.

Para a análise da importância de diferentes dimensões geográficas nas interações dos agentes, elabora-se um conjunto de indicadores de "intensidade das interações por dimensão geográfica" ${ }^{4}$. Estes resumem a intensidade das interações (construídas a partir da ponderação da frequência de ocorrência da interação em cada dimensão geográfica por sua importância). Considerando a interação do conjunto de agentes em um ou mais APLs com um tipo de parceiro (por exemplo, fornecedores

\footnotetext{
4 Estes podem ser formalizados como: $G_{l}^{r}=\frac{1}{n} \sum_{i=1}^{n} n_{i, l} d^{r}{ }_{i, l}$ Onde, Gr é o indicador para um APL (ou conjunto de APLs) da intensidade da interação na dimensão geográfica $r$ com o parceiro do tipo $I, n_{i, l}$ é a importância atribuída pelo agente $i$ a interação com o agente do tipo I, podendo esta assumir os valores 0 para nula importância, 0,33 para baixa importância, 0,66 para média importância e 1 para alta importância; $d^{r}{ }_{i, l}$, indica se 0 agente $i$ interage com o parceiro do tipo / na dimensão geográfica r,assumindo o valor 1 caso sim e 0 caso não.
}

de insumos), resultarão quatro indicadores, com valores variando entre 0 e 1 , referentes às quatro dimensões locacionais utilizadas no questionário.

\section{PROCESSOS INOVATIVOS E INTERATIVOS EM APLS CULTURAIS}

\subsection{Inovação em APLs culturais}

Um primeiro importante indício da relevância da introdução de inovações para as atividades culturais pode ser encontrado no fato de os agentes em todos os oito (08)APLs atribuírem alto grau de importância à "capacidade de introduzir inovações nos produtos/ serviços e processos" (o índice de importância de 0,80), conforme apresentado na Tabela 1.

A alta relevância atribuída à capacidade de introdução de inovações não permanece como mera diretriz, mas se traduz em resultados concretos. Os agentes dos oito APLs culturais apresentam intenso desempenho inovativo. A proporção de agentes que introduziram produtos novos para o mercado de atuação $(45,9 \%)$ e produtos novos apenas para a própria empresa $(60,5 \%)$ é muito mais elevada nos APLs em outros segmentos produtivos. Situação similar é verificada para taxa de introdução de inovações de processo novas para o setor (taxa de $27,8 \%$ ) e novas apenas para a empresa $(61,9 \%)$. Por fim, e mais relevante para as atividades em foco (embora não seja possível

Tabela 1: Importância da capacidade de introdução de inovações e o desempenho de introdução de inovações nos APLs (\%).

\begin{tabular}{l|c|c}
\hline Descrição & $\begin{array}{c}\text { APLs } \\
\text { culturais }\end{array}$ & $\begin{array}{c}\text { Outros } \\
\text { APLs }\end{array}$ \\
\hline $\begin{array}{l}\text { Capacidade de introduzir inovações - } \\
\text { ínice de importância }\end{array}$ & 0,80 & 0,75 \\
\hline Introdução de inovações & & \\
\hline Novo padrão artístico e/ou estético & $64,3 \%$ & n.a. \\
\hline Novo produto ou serviço (para o mercado) & $45,9 \%$ & $23,9 \%$ \\
\hline Novo produto ou serviço (para a empresa) & $60,5 \%$ & $56,3 \%$ \\
\hline Novo processo (para o setor) & $27,8 \%$ & $16,8 \%$ \\
\hline Novo processo (para a empresa) & $61,9 \%$ & $52,0 \%$ \\
\hline Implementação de novas técnicas de gestão & $30,0 \%$ & $33,6 \%$ \\
\hline Mudanças na estrutura organizacional & $27,2 \%$ & $41,3 \%$ \\
\hline Novos conceitos e/ou práticas de marketing & $40,6 \%$ & $36,1 \%$ \\
\hline Novos conceitos e/ou práticas de comercialização & $37,4 \%$ & $40,6 \%$ \\
\hline
\end{tabular}


e não faça sentido comparação com outros segmentos produtivos), destaca-se que a taxa de inovação mais elevada é aquela associada à introdução de novos padrões artísticos e estéticos (64,3\%).

Caracteriza-se, portanto, um padrão inovativo nas atividades culturais, bastante distinto daqueles verificados em diferentes segmentos produtivos não-culturais. As atividades culturais se distinguem, por um lado, por intensa dinâmica de introdução de produtos radicalmente novos, seja em suas características funcionais, seja em seus atributos artísticos e estéticos, sendo ambos muito relevantes para a competitividade/atratividade dos agentes. Por outro lado, as atividades culturais se distinguem por intensa dinâmica de promoção de inovações incrementais nos processos. Este padrão está diretamente relacionado à incorporação de equipamentos existentes no mercado e aos esforços que complementam e possibilitam as inovações de produto. Em especial, este processo está relacionado com o período de realização das pesquisas (2006 a 2010), marcado pela transformação de muitos dos segmentos enfocados, condicionada pela difusão de tecnologias de base digital e as inúmeras oportunidades que estas oferecem. As características dos empreendimentos culturais, usualmente com pequeno contingente de pessoas e padrões organizacionais marcados por equipes flexíveis, contribuem para baixa intensidade de inovações organizacionais relacionadas à gestão $(30 \%)$ e estrutura organizacional $(27,2 \%)$. Por outro lado, a intensa dinâmica inovativa em produtos e em padrões artísticos e estéticos traz consigo esforço considerável de inovações relacionadas ao marketing $(40,6 \%)$ e à comercialização $(37,4 \%)$.

A análise deixa claro o quão intensa e diversificada é esta atividade. Em grande parte, a busca por inovações resulta da percepção, da relevância e da inovação para a competitividade ou atratividade dos produtos e serviços oferecidos, até mesmo nos casos extremos em que os agentes inovadores não se apropriem diretamente dos resultados. Sublinha-se a importância da produção artística e cultural que transcende os parâmetros estritamente econômicos. O prazer pessoal e a importância das manifestações culturais enquanto ritos de socialização são importantes indutores da inovação nas atividades culturais enfocadas.
O desenvolvimento da capacidade de inovar está diretamente relacionado aos processos de aprendizagem e cooperação, essenciais para o desenvolvimento das capacitações dos agentes. Da mesma forma, a análise explicita a importância das articulações e os condicionantes específicos ao ambiente local, que constituem os diversos sistemas produtivos e inovativos locais. Estas relações constituem o objeto da análise que se segue.

\subsection{Processos interativos nos APLs culturais}

Analisa-se, neste item, como se caracterizam os processos sistêmicos decisivos para a geração e difusão de conhecimentos e ampliação das capacitações nos APLS baseados em atividades culturais. Os agentes culturais em todos os APLs enfocados atribuem elevada importância às fontes internas de informação para a aprendizagem, ou seja, aquelas relacionadas aos agentes que integram a própria organização (índice de importância de 0,78). Da mesma forma, aponta-se para a importância da interação com diferentes tipos de agentes externos às próprias organizações. A Tabela 2 apresenta os índices de importância atribuídos a estes agentes.

Um aspecto especialmente interessante é a importância da interação com universidades, institutos de pesquisa $(0,38)$ e centros de capacitação $(0,36)$. Embora não significativas em termos absolutos, estas são sensivelmente maiores do que aquelas verificadas para os APLs em outros segmentos produtivos. Diferente de outros segmentos, observa-se interação mais intensa com áreas relacionadas às artes, como departamentos de artes cênicas, belas artes, cinema, letras, etc. De forma geral, o elevado número de pessoas ocupadas com passagem pela universidade, principalmente em

Tabela 2: Importância das fontes de informação para a aprendizagem - índices de importância.

\begin{tabular}{l|c|c}
\hline Descrição & $\begin{array}{c}\text { APLs } \\
\text { culturais }\end{array}$ & $\begin{array}{c}\text { Outros } \\
\text { APLs }\end{array}$ \\
\hline Fontes internas & 0,78 & 0,60 \\
\hline $\begin{array}{l}\text { Fornecedores de insumos (equipamentos, } \\
\text { materiais) }\end{array}$ & 0,51 & 0,55 \\
\hline Público/espectadores e clientes & 0,73 & 0,72 \\
\hline Concorrentes e outros agentes do segmento & 0,51 & 0,42 \\
\hline Universidades e institutos de pesquisa & 0,38 & 0,17 \\
\hline $\begin{array}{l}\text { Centros de capacitação profissional, artística } \\
\text { ou técnica }\end{array}$ & 0,36 & 0,27 \\
\hline Demais fontes & 0,49 & 0,47 \\
\hline
\end{tabular}


posições de liderança nos empreendimentos culturais, contribui para esta proximidade.

A comparação dos índices de importância para o conjunto dos APLs culturais e para aqueles em segmentos não-culturais sugere haver um quadro parecido, porém com interações mais intensas nas atividades culturais. Em primeiro lugar, como esperado, no caso de atividade de base cultural, a fama e o reconhecimento por parte dos espectadores e do público em geral é de importância central. No caso de atividade permeada por um alto grau de incerteza quanto à "aceitação" e apreciação do produto oferecido, a constante interação com o "consumidor" se revela de suma importância para nortear as atividades destas organizações culturais. Assim, destaca-se o alto grau de importância atribuído a público, espectadores e clientes nos APLs culturais $(0,73)$. Os graus de importância mais elevados, como era de se esperar, ocorrem em casos caracterizados pela realização de apresentações ao vivo (carnaval de Salvador e do Rio de Janeiro e o forró de Fortaleza) e, portanto, em direta interação com o público. O papel central do público enquanto interlocutor dos agentes culturais é explicitado no caso do APL de forró de Fortaleza:

A importância vital desse segmento para a indústria, que comparece aos espetáculos, conjugada com uma relação de interatividade e afetividade acabam direcionando a relação entre oferta e procura numa relação de cumplicidade e lealdade. [...] Tais resultados indicam, portanto, existir uma relação de afetividade/ comercialização entre oferta e demanda. (AMARAL FILHO et al., 2008, p. 38).

Esta citação explicita uma relação imbricada entre a produção e o consumo cultural. Tal característica explicitada para o caso do forró de Fortaleza, mas também presente nos demais casos, é um processo de valoração dos produtos culturais que ocorre na interação. A métrica de valoração empregada é compartilhada pelos indivíduos que compartilham o mesmo pano de fundo cultural.

Os agentes nos APLs culturais atribuem à interação com seus concorrentes e outras empresas no seu segmento importância média, porém superior ao verificado para o conjunto dos APLs não-culturais. Nos diversos estudos realizados com base no referencial de APLs, observa-se uma intensidade relativamente menor de interações com agentes do mesmo segmento, justamente por serem concorrentes e quererem preservar informações estratégicas. Porém, tais respostas se referem à interação entre as organizações. Especialmente nos casos caracterizados por uma dinâmica de disputas sazonais (como o carnaval carioca), as organizações buscam manter segredo sobre suas inovações mais relevantes, reduzindo-se a troca de informações entre elas. Todavia, no nível individual e pessoal, observam-se intensas relações informais de interação em todos os APLs culturais enfocados. Um indício disto é a alta importância atribuída a diferentes instâncias resumidas sob a rubrica "demais fontes". No caso do carnaval do Rio de Janeiro, por exemplo, as trocas informais em encontros de lazer têm alta importância $(0,73)$; nos quatro APLs centrados em atividades cinematográficas e audiovisuais, trocas de informação em conferências, feiras e festivais recebem índices de importância que variam entre 0,70 e 1,00. Isto sugere que as interações sejam predominantemente casuais e informais, ocorrendo nas mais variadas esferas de convívio, especialmente no ambiente local (MOUTINHO et al., 2008; MATOS et al., 2008).

Como proposto acima, as atividades culturais são influenciadas por uma "base de conhecimento" específica. Esta é de natureza essencialmente tácita e está enraizada no território. As atividades culturais nos diversos APLs enfocados evoluíram ao longo de décadas dentro do contexto da evolução deste território, estando estas transformações diretamente associadas à transformação do contexto local como um todo. Verifica-se uma base de conhecimento de caráter essencialmente tácito e enraizado. Um fator que decorre destas características é a importância dos processos de aprendizagem que decorrem da experiência corriqueira dos agentes e das interações informais que ocorrem em diversos espaços de convívio local.

\subsection{Os processos cooperativos}

Uma característica que distingue fortemente as atividades culturais de outros segmentos produtivos é o envolvimento dos agentes em relações cooperativas. A Tabela 3 apresenta o percentual de agentes que cooperam nos APLs culturais e não-culturais e o índice de importância atribuído a cada tipo de parceiro. Destaca-se uma propensão a cooperar muito mais intensa nas atividades culturais $(63,2 \%$ 
dos agentes cooperam) do que em segmentos não-culturais $(49,2 \%)$.

Observam-se vínculos cooperativos com universidades e instituições de pesquisa mais intensos nas atividades culturais (índice de 0,38 ) do que no conjunto dos casos não-culturais $(0,08)$. Da mesma forma, ressaltam-se os índices de importância da cooperação com os agentes produtivos dos respectivos complexos produtivos. Especialmente interessante é o fato de se verificar índices de importância da cooperação com concorrentes e outros agentes do mesmo segmento consideravelmente altos para todos os casos enfocados.

Tais dados confirmam a importância da cooperação nas atividades culturais, tendo em vista os riscos e custos envolvidos na produção cultural. A dificuldade de estabelecimento de relações contratuais bem delimitadas, a frequência e espontaneidade das interações convergem para explicar a importância de relações cooperativas, o estabelecimento de parcerias, na maioria das vezes baseadas apenas na reputação e confiança das partes envolvidas.

Conforme destacado em diferentes áreas de conhecimento e suas análises da produção cultural, estas ocorrem através da interação de diversos agentes com capacitações e ativos complementares. Para além de complementaridades produtivas estas inter-relações se traduzem na constituição de relações cooperativas, favorecidas por relações de confiança interesses convergentes. Convergência esta

Tabela 3: Percentual de agentes que cooperam e a importância da cooperação com diferentes parceiros nos APLs - índices de importância.

\begin{tabular}{l|c|c}
\hline Descrição & $\begin{array}{c}\text { APLs } \\
\text { culturais }\end{array}$ & $\begin{array}{c}\text { Outros } \\
\text { APLs }\end{array}$ \\
\hline $\begin{array}{l}\text { Agentes que cooperam (\%) } \\
\text { Importância da cooperação }\end{array}$ & $63,2 \%$ & $49,2 \%$ \\
\hline $\begin{array}{l}\text { Fornecedores de insumos (equipamentos, } \\
\text { materiais) }\end{array}$ & 0,55 & 0,20 \\
\hline Público/espectadores e clientes & 0,61 & 0,25 \\
\hline $\begin{array}{l}\text { Concorrentes e outros agentes do segmento } \\
\text { Universidades e institutos de pesquisa }\end{array}$ & 0,50 & 0,17 \\
\hline $\begin{array}{l}\text { Centros de capacitação profissional, } \\
\text { artística e técnica }\end{array}$ & 0,30 & 0,08 \\
\hline Demais agentes & 0,35 & 0,08 \\
\hline
\end{tabular}

que está diretamente relacionada à qualidade de atrativos que dependem do desempenho dos diversos agentes envolvidos.

\subsection{A relevância das interações locais}

As questões que investigam as trocas de informação para a aprendizagem e os processos cooperativos trazem riquíssima informação acerca da localização dos interlocutores das empresas. A partir destes dados, é possível verificar o quão intenso são estes processos em diferentes esferas. Aplica-se o conjunto de indicadores de intensidade das interações por dimensão geográfica, propostos acima. A Figura1 resume a intensidade dos processos interativos com os principais interlocutores para o conjunto dos agentes entrevistados nos oito APLs culturais.

As informações contidas no quadro constituem evidência concreta da ocorrência de significativas economias de aprendizado. As trocas de informação mais intensas ocorrem no ambiente local, figurando a interação com agentes em outros estados do país como a segunda mais importante. Em primeiro lugar, destaca-se a intensa interação com clientes/público. Conforme analisado acima, o alto índice de importância da interação com estes está diretamente associado a atividades presenciais e marcado por alta incerteza. Mas o quadro acima oferece informações mais detaIhadas que apenas o grau de importância apresentado acima. Observa-se que a interação com clientes e espectadores é mais intensa na esfera local do que nas demais dimensões, o que explicita a importância da economia local enquanto demandante dinamizador das atividades produtivas culturais, mas também enquanto consumidor ativo, muitas vezes co-produtor imprescindível daquilo que é consumido.

Estes resultados confirmam as proposições presentes em diversas áreas de conhecimento, mas destacadas na geografia. Os sentimentos de pertencimento e identidade são construídos culturalmente; e esta construção se dá em bases concretas definidas pela base territorial local (SANTOS, 2000). No caso de atividades culturais enraizadas em um território, as interações medidas na aplicação dos questionários constituem justamente este processo de constante reconstrução de identidades locais. Os símbolos produzidos e seu ato de produção e consumo são traduções imediatas deste referencial coletivo. 
De forma similar ao caso dos consumidores, observase uma interação sensivelmente mais intensa com os fornecedores no âmbito local, o que sugere uma razoável estruturação das cadeias produtivas nesta dimensão geográfica. Em muitos casos os insumos são bastante específicos e são associados à cultura local.

Os resultados reforçam o argumento colocado acima de que se verifica, nas atividades culturais, uma densa articulação local, com a presença de agentes importantes em todos os elos do complexo produtivo no local. Estas articulações locais são reforçadas pela presença de muitos serviços complementares que podem ser caracterizados como "non-tradables", sendo necessariamente providos localmente. Os fortes vínculos interativos e de cooperação locais com agentes em diferentes elos do complexo produtivo constituem forte indicativo da existência de importantes economias de aglomeração na produção.

Por fim, a importância relativamente mais elevada da interação com universidades e centros de pesquisa foi discutida acima. Os dados da figura complementam tal análise, sendo possível verificar que grande parte destas interações se dá no âmbito local, o que explicita uma interessante articulação entre os quadros destas instituições e a própria cultura local. Em grande parte, os quadros destas instituições, principalmente o corpo discente, são indivíduos que originam ou vivem na região, compartilham dos mesmos valores e hábitos, sendo, portanto, parte constituinte daquele território, o que contribui para que esta interação ocorra de forma mais fácil, comprometida e sistêmica.

\section{EXTERNALIDADES DINÂMICAS E COLETIVAS DO AMBIENTE LOCAL}

O fazer cultural, o desempenho produtivo e inovativo e a atratividade/competitividade resultante são condicionados por questões territoriais, externalidades estáticas e dinâmicas que dependem do território e da conformação de suas atividades produtivas. As informações sobre as diferentes externalidades do ambiente local permitem identificar os potenciais benefícios da inserção dos agentes em arranjos e sistemas produtivos e inovativos locais.

A qualidade da mão-de-obra constitui um dos fatores mais relevantes para a competitividade/atratividade

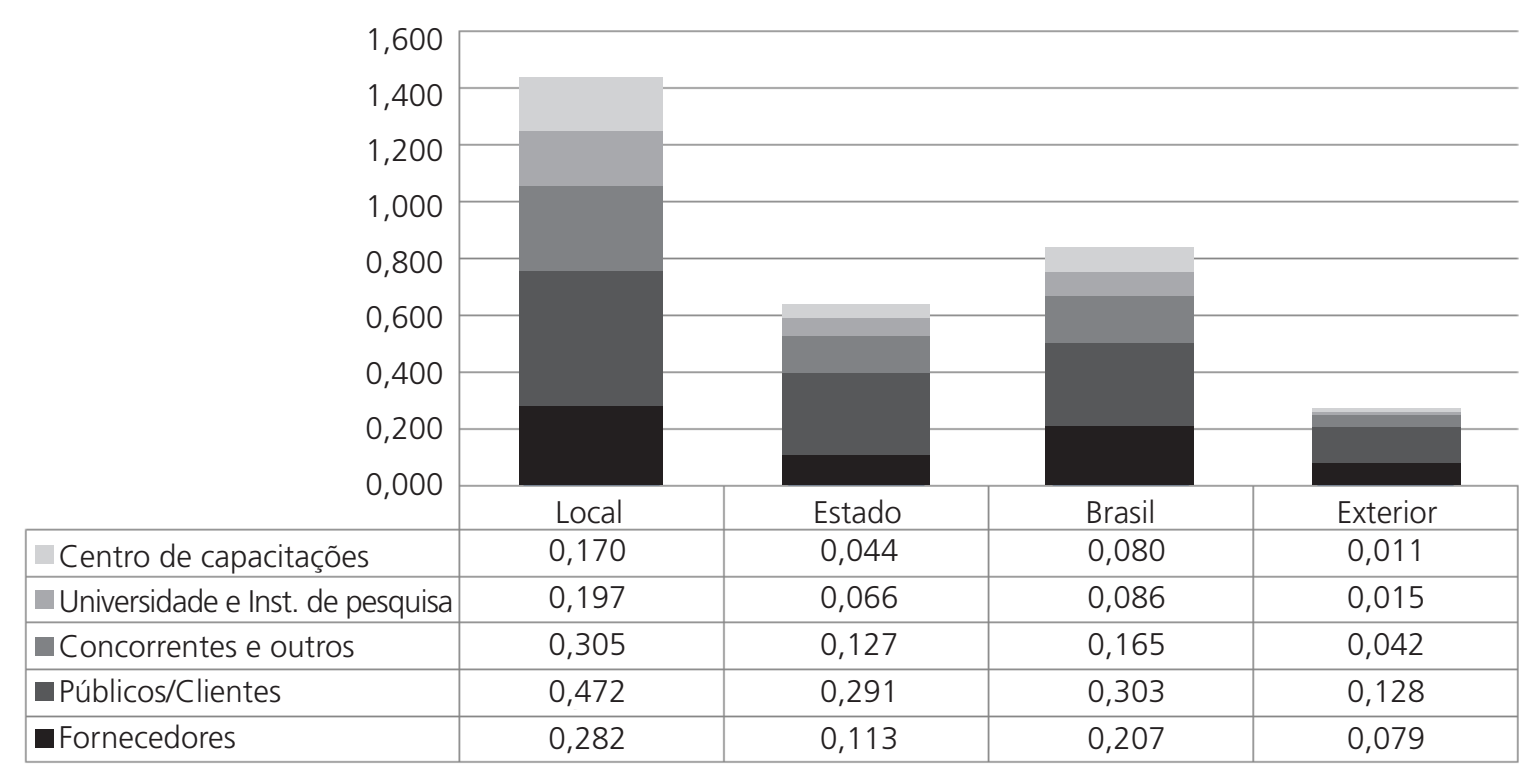

Figura 1: Intensidade ponderada das interações com diferentes agentes no ambiente local, no resto do estado, em outros estados e no exterior. 
dos APLs culturais. A disponibilidade de mão de obra qualificada é apontada como importante qualidade do ambiente local em todos os casos enfocados (índice de $0,75)$. A partir desta observação, fica evidente o quão importante é o conjunto de pessoas atuantes na produção cultural específica a cada APL e o quão importante são os conhecimentos tácitos, as habilidades, que estes possuem. Em grande parte, estas respostas fazem referência à variada gama de prestadores de serviços complementares à produção presentes no local, com os quais são mantidas intensas relações. Na mesma linha de análise, destaca-se a baixa importância atribuída pela maioria dos entrevistados quanto ao baixo custo da mão-de-obra local (índice médio de 0,42). Embora respondentes individuais em diferentes pesquisas sugiram que tal resposta esteja relacionada ao fato de a mão de obra especializada não possuir baixo custo, a maioria dos respondentes associa esta baixa importância ao fato de este critério não ser um determinante competitivo relevante.

Caracteriza-se, portanto, uma importante dimensão de distinção das atividades culturais com relação a muitos outros segmentos produtivos. Baixos custos de insumos e de mão de obra constituem justamente aqueles elementos competitivos que podem ser caracterizados como espúrios. Estes fatores estão mais fortemente associados a segmentos nos quais as empresas podem escolher onde constituir sua estrutura produtiva, se beneficiando destas vantagens de custo de forma dissociada e pouco enraizada no território. As atividades culturais representam o caso diametralmente oposto, fortemente enraizado e articulado com a economia local, conforme observado na Tabela 4.

A importância da proximidade de fornecedores é maior do que nos casos baseados em outros segmentos produtivos, o que aponta para significativas articulações comerciais e de interação locais à montante na cadeia produtiva. Da mesma forma, a importância da presença local de serviços técnicos especializados aponta para importantes articulações produtivas locais.

Os agentes nos diferentes APLs apontam que a existência de canais de divulgação e comercialização, bem como a atração de clientes ao local, constitui significativa vantagem do ambiente local. Da mesma forma, na maioria dos APLs, a proximidade com clientes/espectadores constitui significativo diferencial do ambiente local. Destacam-se, como esperado, aqueles casos caracterizados por espetáculos ao vivo e presenciais. Nestes APLs, o público é especialmente importante porque constitui parte do próprio atrativo, na medida em que a sua participação é parte imprescindível do "produto final" resultante que eles mesmos consomem.

Esta discussão ressalta a importância do caráter coletivo de esforços produtivos e inovativos em tal sistema. Como demonstrado neste trabalho, a ênfase e foco de análise no indivíduo não permite, por si só, entender a dinâmica destes sistemas. Mostra-se necessário avançar para além das estratégias individuais e analisar as estratégias, inovações e esforços de preservação que são empreendidos coletivamente e cujos resultados são apropriados, igualmente, de forma coletiva. Esta constitui a instância central, na qual são estabelecidas as vantagens comparativas com relação a outras opções. Muitos fatores considerados importantes vantagens do ambiente local em diversos APL são de caráter explicitamente coletivo. À cultura local, na qual se encontram enraizadas as tradições das práticas culturais específicas, foi atribuído o mais alto índice de importância $(0,89)$.

Alguns dos fatores abordados acima, que constituem elementos centrais para a realização eficiente e atratividade dos produtos e serviços culturais, além de serem essencialmente coletivos, possuem características de bens públicos. Dificilmente agentes individuais se encontram dispostos a comprometer recursos em fatores como a organização do espaço público (tráfego, segurança, limpeza etc.), provisão da infra-estrutura para desfiles e apresentações, divulgação do desfile como um todo.

Tabela 4: Vantagens da Localização no ambiente local em diferentes APLs - índices de Importância.

\begin{tabular}{l|c|c} 
Externalidades & $\begin{array}{c}\text { APLs } \\
\text { culturais }\end{array}$ & $\begin{array}{c}\text { Outros } \\
\text { APLs }\end{array}$ \\
\hline $\begin{array}{l}\text { Disponibilidade de Mão de obra Qualificada - } \\
\text { EXTERNQMDO }\end{array}$ & 0,75 & 0,69 \\
\hline Baixo custo da mão-de-obra - EXTERNCMDO & 0,42 & 0,53 \\
\hline $\begin{array}{l}\text { Proximidade com Fornecedores - } \\
\text { EXTERNFORNINS\&PEÇ }\end{array}$ & 0,59 & 0,57 \\
\hline Proximidade com clientes consumidores & 0,67 & 0,58 \\
\hline $\begin{array}{l}\text { Canais de divulgação e comercialização/ } \\
\text { atração de clientes }\end{array}$ & 0,60 & n.d. \\
\hline $\begin{array}{l}\text { Disponibilidade Serviços Técnicos } \\
\text { especializados - EXTRNSERV }\end{array}$ & 0,60 & 0,58 \\
\hline Cultura local & 0,89 & n.d. \\
\hline Infraestrutura física & 0,67 & 0,62 \\
\hline Existência de Programas de apoio e promoção & 0,48 & 0,37 \\
\hline & &
\end{tabular}


O exemplo mais emblemático de coordenação centralizada e hierarquizada se dá no caso de Campina Grande. A prefeitura da cidade é a principal produtora da festa, se "apoderando" de uma manifestação cultural inicialmente espontânea, fortalecendo as parcerias público-privadas, conforme destaca Moreira et al (2012). Ela é responsável pela instalação do Parque do Povo (local onde ocorre o São João) e toda sua infraestrutura, contratando os prestadores de serviços relacionados à infraestrutura, barraqueiros e grupos artísticos, além de gerir os recursos provenientes de patrocínios geridos pelo governo estadual (MOUTINHO et al., 2006). De forma similar, coube ao governo do estado fluminense a construção do sambódromo e à prefeitura carioca a construção da "cidade do samba". Cabe ao poder público a provisão da infraestrutura dos circuitos de desfile nas ruas nos dois casos de festas carnavalescas.

Estas grandes transformações da infraestrutura constituem alguns exemplos de inovações que foram gestadas coletivamente e executadas pelo poder público ou por este em parceria com diferentes agentes que compõem o arcabouço institucional local, o que conduziu a importantes transformações positivas dos sistemas como um todo, dados os benefícios diretos ou indiretos sobre a ampla gama de atores envolvidos. Relacionadas a tal aspecto figuram as respostas dos agentes culturais sobre as vantagens do ambiente local relacionadas à existência de programas de apoio e promoção. Todavia, a atuação do poder público no apoio a manifestações culturais não está livre de críticas, sendo influenciada por instâncias de poder político e econômico e interesses divergentes, podendo, inclusive, representar riscos para a própria continuidade das manifestações específicas.

\section{DA COMPETITIVIDADE/ATRATIVIDADE PARA A SUSTENTABILIDADE}

\subsection{Riqueza cultural, preservação e inovação}

Na base da discussão acerca da sustentabilidade das atividades culturais estão os valores, as práticas, os hábitos coletivos que dão caráter único a dada manifestação. Os variados esforços inovativos apontados acima têm contribuído para atrair maior número de consumidores ou espectadores com importante impacto sobre o desenvolvimento local. Os diversos casos de
APLs culturais representam experiências de aproveitamento econômico direto ou indireto desta base de riqueza. Nos diversos casos enfocados neste estudo, a "cultura local" é apontada como determinante central da competitividade/atratividade. A questão central diz respeito a até que ponto este "recurso", a base cultural local, pode representar um elemento de competitividade dinâmica e sustentável.

Este estoque de riqueza se encontra, em grande parte, materializado nas habilidades dos indivíduos que integram os empreendimentos culturais. Os referidos conhecimentos são de caráter essencialmente tácito. A consideração dos fatores determinantes da atratividade e sustentabilidade destes APLS aponta para a centralidade de esforços de preservação. Quando analisadas as longas tradições envolvendo a evolução das manifestações culturais, seu processo de evolução ao longo de décadas levou a significativas transformações, tornando-as grandes espetáculos ou relevantes manifestações com significativos impactos econômicos. Porém, verificase a manutenção de características específicas que permitem identificar esta manifestação cultural e distingui-la das demais.

Na maioria dos casos enfocados, a centralidade destes aspectos não decorre da simples permanência destes, na qual o presente é passivamente influenciado pelo passado, mas sim do dispêndio de recursos e esforços para a preservação dos mesmos dados na consciência dos agentes envolvidos quanto a sua relevância para a atratividade e sustentabilidade. Tais esforços ficam evidenciados em uma pergunta especificamente relacionada à valorização e aos esforços dos agentes para com estes aspectos locais.

Conforme apresentado na Tabela 5, os respondentes em todos os APLs são uníssonos em atribuir alta importância aos aspectos culturais do ambiente local (índice de importância de 0,93) e aos aspectos materiais e naturais do ambiente local $(0,78)$. Porém, mais relevante que a importância atribuída a estas dimensões é o esforço ativo acusado pelos respondentes de atuar na preservação dos elementos elencados. Mais de $80 \%$ dos agentes apresentam esforços ativos e contínuos direcionados à preservação do que consideram seu patrimônio cultural. 
Tabela 5: Relação dos agentes em APLs culturais com aspectos da Cultura Local.

\begin{tabular}{l|c|c}
\hline Características & $\begin{array}{c}\text { Grau de } \\
\text { importância }\end{array}$ & $\begin{array}{c}\text { Empenho } \\
\text { (\%) }\end{array}$ \\
\hline $\begin{array}{l}\text { Preservação/valorização de aspectos } \\
\text { culturais (patrimônio material e } \\
\text { imaterial) }\end{array}$ & 0,93 & $80,5 \%$ \\
\hline $\begin{array}{l}\text { Preservação de características do } \\
\text { ambiente (natureza, arquitetura, etc.) }\end{array}$ & 0,78 & $62,0 \%$ \\
\hline
\end{tabular}

O estudo do carnaval do Rio de Janeiro verificou importantes esforços de preservação. "Não deixe o samba morrer; não deixe o samba acabar; o morro foi feito de samba". Esta famosa música representa bem este espírito. Representa ainda mais, pois explicita a imbricada associação de uma manifestação cultural com seu território. É por isso que os entrevistados apontaram com grande frequência seus esforços ativos de preservação do ritmo do samba e dos instrumentos tradicionalmente empregados na sua execução. A importância conferida às alas da velha guarda e das crianças ressalta também a importância da convergência de diferentes gerações (MATOS, 2007).

Esta última questão chama atenção para a importância da transmissão entre gerações dos conhecimentos e valores relacionados às manifestações culturais. Observa-se, portanto, no caso das atividades analisadas, que a manutenção do estoque de riqueza, que pode ser denominado "capital cultural" está diretamente associada à sua difusão entre os agentes locais, à sua transformação com o processo criativo e à preservação daquelas características chave que o tornam único e específico.

Estes exemplos apontam na direção contrária daquilo que pode ser caracterizado como suposta dicotomia "inovação versus preservação". Os casos analisados apresentam evidências para a proposição de que inovação e preservação podem sim se complementar em um processo virtuoso de criação do novo. Elementos de novidade, contextualizados em um arcabouço de práticas e valores específicos, podem contribuir para a contínua renovação da atratividade e competitividade de muitas manifestações culturais. A questão que se coloca então é o que determina uma transformação e reinvenção virtuosa de manifestações culturais e o que a distingue de um processo de descaracterização e perda de coerência e atratividade.

\section{CONCLUSÃO}

Este estudo partiu da aplicação do referencial de Arranjos e Sistemas Produtivos e Inovativos Locais para a análise dos determinantes da competitividade/atratividade de atividades culturais. Observou-se como estas atividades apresentam padrões de inovação e processos interativos muito particulares e decisivos para seu desempenho. Observou-se que a consideração das atividades culturais enquanto potenciais dinamizadores do desenvolvimento local passam pela consideração de fatores específicos. Além de discutir a competitividade dos empreendimentos e dos APLs é preciso discutir sua sustentabilidade, em face de processos diversos de transformação e apropriação.

O desenvolvimento substantivo destas atividades passa pelo cultivo e pelo fortalecimento dos valores da própria cultura. Se esta argumentação é válida na esfera nacional, ela é igualmente pertinente para a esfera local. A base para o desenvolvimento local virtuoso passa, dentre outros elementos, necessariamente pela valorização e fortalecimento da própria cultura local.

A cultura de um local tem maiores condições de transcender o status de folclore e configurar-se como pujante manifestação, quando esta constitui uma base para a geração de riqueza. Da mesma forma que o argumento difundido entre aqueles que tratam sobre o tema da sustentabilidade, a forma mais eficiente de manter uma floresta é encontrar modelos de exploração que façam com que ela valha mais de pé do que cortada. Argumenta-se que é preciso desenvolver meios de atribuir valor econômico (valor de uso e de troca) real à riqueza cultural local para que esta se torne um elemento dinâmico. A riqueza cultural, ao constituir,além de base de fruição, também base de geração de riqueza, induz a um esforço contínuo e ampliado de sua reprodução.

Como argumentado acima, este esforço de reprodução e reinvenção moderna destas culturas só apresentará algum grau de coerência quando conduzida pelos representantes orgânicos desta tradição. Não se trata da escolha entre preservar ou inovar, mas sim de um processo de reinvenção e transformação coerente e contextualizado. Contudo, para que os integrantes daquele grupo social que incorporam e representam tal cultura despendam esforços para sua reprodução, estes 
também têm que se apropriar de forma direta ou indireta dos retornos simbólicos e pecuniários de sua atividade.

Não se trata da escolha entre a cultura e a economia, como supunham os tradicionais estudos da "indústria cultural", mas sim da escolha entre uma exploração econômica alheia e intensiva e um aproveitamento consciente, contextualizado e sustentável. A dimensão espetáculo, a dimensão midiática, não é necessariamente negativa. Pelo contrário, ela tem o potencial de arregimentar as bases materiais para a reprodução dela mesma, mas também da dimensão mais orgânica e socialmente enraizada.

Entende-se, portanto, o desenvolvimento tanto nacional como local como um processo de transformação social, cultural, econômico e político. Nesta perspectiva, o desenvolvimento só pode se efetivar quando está fundamentado na cultura e nas tradições de um povo ou coletividade, pois constitui um processo diretamente vinculado aos valores de cada grupo social.

\section{REFERÊNCIAS}

AMARAL FILHO, J. Arranjo produtivo do forró em Fortaleza, Ceará. Nota técnica do projeto de pesquisa 'Arranjos e Sistemas Produtivos e Inovativos Locais em Áreas Intensivas em Cultura e Mobilizadoras do Desenvolvimento Social'. Rio de Janeiro: RedeSist-IE/UFRJ; Sebrae, 2008. Disponível em: <http://www.redesist.ie.ufrj.br>. Acesso em: 1 mar. 2011.

BARBIERI DA ROSA, L. A.; KNEIPP, M. J.; BICHUETI, R. S.; GOMES, M. C.; CESARO, O. A.; ORTIGARA, R. M. A Maturidade inovadora das empresas da rede de pedras preciosas de Ametista do Sul. Revista Gestão e Regionalidade, v29, n 85, 2013.

BRITTO, J. Relevância de pequenas e médias empresas em arranjos produtivos na indústria brasileira: uma análise exploratória. In: LASTRES, H. M. M., CASSIOLATO, J. E.; MACIEL, M. L. (org.) Pequena empresa: cooperação e desenvolvimento local. Cap. 19 (p. 327-344). Rio de Janeiro: Relume Dumará: UFRJ, Instituto de Economia. 2003.

. Cooperação e aprendizado em arranjos produtivos locais: em busca de um referencial analítico. Nota técnica n. 4 do Projeto de Pesquisa Aprendizado, capacitação e cooperação em arranjos produtivos e inovativos locais de MPEs: implicações para políticas. 2004. Disponível em: <http://redesist.ie.ufrj.br/>. Acesso em: 05 maio 2006.

CAMPOS, R. R.; CARIO, S. A. F.; NICOLAU, J. A.; VARGAS, $G$. Aprendizagem por interação: pequenas empresas em sistemas produtivos e inovativos locais. In: LASTRES, H. M. M.; CASSIOLATO, J. E.; MACIEL, M. L. (org.). Pequena empresa: cooperação e desenvolvimento local. Cap. 3 (p. 51-66). Rio de Janeiro: Relume Dumará, 2003.
CASSIOLATO, J. E.; LASTRES, H. M. M. Inovação, globalização e as novas políticas de desenvolvimento industrial e tecnológico. In: CASSIOLATO, J. E. et al. (ed.). Globalização e inovação localizada: experiências de sistemas locais no âmbito do Mercosul. Cap. 21 (p. 767-799). Brasília: IBICT/MCT, 1999.

CASSIOLATO, J. E.; SZAPIRO, M. Uma caracterização de arranjos produtivos locais de micro e pequenas empresas. In: LASTRES, H. M. M.; CASSIOLATO, J. E.; MACIEL, M. L. (org.). Pequena empresa: cooperação e desenvolvimento local. Cap. 2 (pp. 35- 50). Rio de Janeiro: Relume Dumará. 2003.

CAVES, R. E. Contracts between arts and commerce. Journal of Economic Perspectives, v. 17, n. 2, p. 73-83, 2003.

CIMOLI, M.; GIUSTA, M. Innovation and patterns of learning: a survey of evolutionary theories. In: BATTEN, D. F. et al (eds.). Learning, innovation, and urban evolution. Cap. 2 (pp. 11 - 44). Boston: Kluwer Academic Publishers. 2000.

COHENDET, P. STEINMUELLER, W. E. The codification of knowledge: a conceptual and empirical exploration. Industrial and Corporate Change, v. 9, n. 2, p. 195-209, 2000.

FAJNZYLBER, F. Competitividad internacional: evolución y lecciones. Revista de La CEPAL, n. 36, p. 7-24, 1988.

FURTADO, C. Cultura e Desenvolvimento em época de crise. Rio de Janeiro: Paz e Terra, 1984.

. Teoria e Política do Desenvolvimento Econômico. São Paulo: Abril Cultural, 1983. 


\section{REFERÊNCIAS}

MATOS, M. P. O sistema produtivo e inovativo local do carnaval carioca.Dissertação de Mestrado em Economia. Programa de Pós-Graduação em Economia,Universidade Federal Fluminense, Niterói, 2007.

Atividades culturais em perspectiva sistêmica. Tese de Doutorado em Economia. Programa de Pós-Graduação em Economia, Universidade Federal Fluminense, Niterói, 2011.

MOREIRA, C. L. BRESCIANI, P. L.; VIEIRA, P. T. S.; QUEIROZ, M. C. G. As Parcerias Público-Privadas no Estado de São Paulo: A contribuição ao processo de descentralização da administração pública. Revista Gestão e Regionalidade, v. 28, n. 84, p. 33-47, 2012.

MOUTINHO, L. M. G.; CAVALCANTI FILHO, P. F. M. B. O SPIL do audiovisual de Recife. Nota técnica do projeto de pesquisa 'Arranjos e Sistemas Produtivos e Inovativos Locais em Áreas Intensivas em Cultura e Mobilizadoras do Desenvolvimento Social'. Rio de Janeiro: RedeSist-IE/ UFRJ; Sebrae, 2008.

MOUTINHO, L. M. G.; CAVALCANTI FILHO, P. F. M. B.; KEHRLE, L. R.; CAMPOS, L.H. R. O maior São João do mundo em Campina Grande. Nota técnica do projeto de pesquisa 'Mobilizando conhecimentos para desenvolver arranjos e sistemas produtivos e inovativos locais de micro e pequenas empresas no Brasil'. Rio de Janeiro: RedeSist-IE/ UFRJ; Sebrae, 2006.

O'CONNOR, J. Cultural intermediaries and cultural industries. In: VERWIJNEN, J.; LEHTOVUORI, P. (ed.). Creative Cities. Helsinki, University of Art and Design Publishing Unit. 1999.

SANTOS, M. Por uma outra globalização - do pensamento único à consciência universal. São Paulo: Record, 2000.

LUNVALL, B.-Å. (ed.). National systems of innovation: towards a theory of innovation and interactive learning. Londres: Pinter, 1992.

MATOS, M. P.; GUIMARÃES, V.; SOUZA, R. G. O sistema produtivo e inovativo local de audiovisual do Rio de Janeiro. Nota técnica do projeto de pesquisa 'Arranjos e Sistemas Produtivos e Inovativos Locais em Áreas Intensivas em Cultura e Mobilizadoras do Desenvolvimento Social'. Rio de Janeiro: RedeSist-IE/UFRJ; Sebrae, 2008. 